Title: Emotional intimacy power predicts different sexual experiences for men and women.

Corresponding Author:

Dr Gaynor L. Edwards

School of Psychology

Murdoch University

South Street

Murdoch

Western Australia

6150.

Phone: +61 893607382

Fax: +61 893606492

Email: G.Edwards@murdoch.edu.au

Co-Authors: Professor Bonnie L Barber

School of Psychology

Murdoch University

Dr Suzanne Dziurawiec

School of Psychology

Murdoch University 


\begin{abstract}
Those who are more emotionally invested in relationships have less power than their partners. Furthermore, less powerful individuals may attempt to equalize power imbalances by offering rewards to their partner and using sex and condom use as exchange resources. Australian young adults reported their condom use and pressured sex experiences in both romantic $(n=708)$ and casual ( $n=118$ ) relationships. Results showed that greater power (lower relative emotional investment) predicted more condom use among those wanting to use condoms. In casual relationships, an interaction with gender showed that women in particular used condoms more when they had more power. Power also interacted with gender for pressured sex and unexpectedly, men who had more power experienced more pressured sex. The possibility that condom use and pressured sex have different meanings for men and women is explored. Keywords: Power, Gender, Pressured sex, Condom use
\end{abstract}




\section{Emotional intimacy power predicts different sexual experiences for men and women.}

Sexual behaviour has often been viewed as individual risk behaviour. However, sexual behaviour is inherently social in nature, and is negotiated between two individuals. Inevitably, when two people have competing desires or motivations, one partner will experience a more favourable outcome than the other. One factor that is likely to determine which partner most often experiences their desired outcome is power. Power has been defined as the capacity to have influence over another's attitudes or behaviour (Tschann, Adler, Millstein, Gurvey, \& Ellen, 2002). Applied to sexual behaviour, more powerful individuals should have the most influence over how sexual intercourse and condom use are negotiated.

One theory used to understand the balance of power in relationships is social exchange theory which highlights the importance of identifying the rewards and costs of being in a relationship (Thibaut \& Kelley, 1959). Sometimes, a person may receive fewer rewards from being in the relationship than their partner does. For example, partners who are less in love may not find the relationship as enjoyable or rewarding as partners who are more emotionally invested. This phenomenon is known as the principle of least interest (Sprecher, Schmeeckle, \& Felmlee, 2006; Waller \& Hill, 1951), whereby the person who is the least in love has the most power in the relationship. The reason that the person who is least in love has the most power is that he/she has less invested in the relationship, and therefore has less to lose if the relationship were to end.

Less powerful partners may engage in sexual behaviours because they are consistent with what they perceive their partners to want, rather than what they want themselves. Sexual compliance can take various, forms with two examples being whether an individual decides to engage in sex, or have unprotected sex, against their wishes. Sexual compliance can have 
important health implications, with condom non-use increasing the risk of sexually transmitted infections and unplanned pregnancies, and pressured sex (having sex due to partner pressure) being associated with reduced well-being (Moore \& Rosenthal, 2006; Zweig, Barber, \& Eccles, 1997).

There is evidence to suggest that both men and women sometimes engage in unwanted sexual activity (Morgan \& Zurbriggen, 2007; Muehlenhard \& Cook, 1988; O'Sullivan \& Allgeier, 1998; Vannier \& O'Sullivan, 2010), but it is generally understood to be more common among young women than young men (Impett \& Peplau, 2003). The most common reason for engaging in unwanted consensual sexual activity with a partner was to satisfy one's partner's needs (O’Sullivan \& Allgeier). Additionally, individuals may make condom use decisions based on their partner's preferences, rather than their own. In both instances, sexual compliance entails making decisions about one's own sexual behaviour based on the perceived desires of one's partner, rather than on one’s own desires (Impett \& Peplau, 2003). Viewed from social exchange theory, the act of complying with one's partner's perceived desires for sexual intercourse and condom use may be a way of offering rewards to one's partner. This paper examines the link between power and sexual behaviour in romantic and casual relationships, and the ways in which power predicts the sexual behaviour of men and women in different and meaningful ways.

\section{Power and Sexual Behaviour}

Although the link between power and sexual behaviour appears inherent, there is limited evidence regarding how power relates to unwanted sex. Among female adolescents, the ability to refuse unwanted sex has been linked with holding the belief that male control in relationships is non-normative (Sionean, et al., 2002). Additionally, female adolescents with less power report that their boyfriends have the most say about when they have sex (Wang, Wang, \& Hsu, 2007). 
Women in qualitative studies have also described pressured sex as being linked to power in relationships, with some accounts supporting the idea of sex being used as an exchange resource (Morgan \& Zurbriggen, 2007). The research literature suggests that less powerful women have more pressured sex. However, little is known about how power relates to pressured sex for men. Engaging in unwanted sex is not the only way that power may manifest in sexual behaviour. Some research has found that those with greater power use condoms more often (Billy, Grady, \& Sill, 2009; Buysse \& Van Oost, 1997; Jorgensen, King, \& Torrey, 1980; Pulerwitz, Amaro, De Jong, Gortmaker, \& Rudd, 2002; Pulerwitz, Gortmaker, \& DeJong, 2000). However other researchers have found no relationship between general power and condom use (Bralock \& Koniak-Griffin, 2007; Cabral, Pulley, Artz, Brill, \& Macaluso, 1998; Harvey, Bird, Galavotti, Duncan, \& Greenberg, 2002; Teitelman, Ratcliffe, Morales-Aleman, \& Sullivan, 2008). Research taking into account individuals' desires to use condoms has found that those with more power reported condom use behaviour that was consistent with their own desires (Tschann, et.al, 2002; Wang, et al., 2007). Condom use behaviour can only be conceptualised as compliance when the use or nonuse of condoms is inconsistent with one's own desires, and so it is important to consider condom use desires. Little is known about condom use behavior that is specific to individuals who desire to use condoms. From a health perspective, it would be valuable to know whether low power prevents condom use among those who want to use condoms. This study aims to fill some of these gaps in the literature.

\section{Measurement of Power}

Some studies have found that a significant effect of power on condom use depends on the measure of power used (Harvey, et al., 2002; Jorgensen, et al., 1980; Tschann, et al., 2002). For example, Harvey and colleagues (2002) did not find general power to relate to condom use, but 
they did find that those who reported decision making power around condom use, used condoms more. Power has been measured in many different ways across studies, including who has more financial resources (Billy, et al., 2009; Sionean, et al., 2002), who wins arguments (Jorgensen, et al., 1980), who makes the decisions in the relationship (Cabral, et al., 1998; Harvey, et al., 2002; Jorgensen, et al., 1980; Tschann, et al., 2002), who is more emotionally invested (Billy, et al., 2009; Felmlee, 1994; Sprecher \& Felmlee, 1997; Tschann, et al., 2002) and simply by directly asking who has the most power (Cabral, et al., 1998; Felmlee, 1994; Sprecher \& Felmlee, 1997; Tschann, et al., 2002). Some authors have separately investigated multiple aspects of power, and others have used a composite measure, averaging the balance of power across these domains. It is likely that these different measures of power are tapping into different aspects of power. Two issues are important to consider when measuring power in romantic or casual relationships. The first relates to whether the power measure is assessing potential power or an outcome of power. The second relates to whether the domain of power is relevant to the sample.

Bacharach and Lawler (1981) differentiate between potential power and power outcomes. Measures of power outcomes emphasise the end result, or behavioural manifestation of power. Some examples of power outcomes include who wins conflicts, who determines how the couple spends their leisure time, and who controls the use of birth control. Potential power by contrast, may be seen as a precursor to power outcomes and is a structural element in a dyad. For example, an individual will gain potential power if he/she is better looking, is less dependent on the relationship, or has more financial or social resources than the partner. Of the studies reviewed above, some investigate potential power (e.g. emotional investment discrepancy), whereas others focus on power outcomes (e.g. who makes decisions) as predictors of sexual behaviour. We argue that this differentiation is important, as power outcomes reflect a 
consequence of power, whereas potential power reflects the origins of power. In other words, measures of power outcomes can indicate who holds power, whereas measures of potential power can demonstrate why an individual holds power.

When choosing a measure of power to investigate, it may also be important to consider the particular aspect of power that is relevant to the sample being studied. Tschann and colleagues (2002) highlight the notion that the resources a person brings to a relationship are a basis of power, or potential power, and the more resources brought, the more powerful the individual is. For example, greater financial resources lead to greater potential power. However, for young adult romantic relationships in which the couple is unmarried, financial resources may be of little relevance. Like Tschann and colleagues, we argue that emotional commitment to a partner is of more relevance to unmarried young adults. Individuals who are committed to relationships are dependent upon the relationship, and thus may be more willing to sacrifice their own needs for the sake of their partner (Rusbult \& Buunk, 1993). This idea is consistent with the principle of least interest which states that the most dependent partner is the least powerful (Sprecher, et al., 2006; Waller \& Hill, 1951). It may be that those who are more dependent on the relationship will have more to lose if the relationship were to end. These partners may be more willing to compromise their own desires for the sake of relationship maintenance.

Emotional intimacy as a domain of power has previously been investigated as a predictor of condom use in adolescent romantic relationships (Tschann, et al., 2002). Adolescents with more emotional intimacy power (in other words, those less emotionally invested than their partners) were more likely to have their condom use desires enacted in romantic relationships. This meant that more powerful individuals were more likely to use condoms the last time they had sex if they wanted to use condoms, and were less likely to use condoms if they did not want 
to use condoms. However Tschann and colleagues did not test this relationship in casual relationship contexts.

\section{Power and Gender}

The outcome of power in a relationship is also likely to depend on the gender of the individual. Many studies have found that the way in which the least powerful person in the relationship experiences sexual outcomes is linked to their gender (Bruhin, 2003; Buysse \& Van Oost, 1997; Jorgensen, et al., 1980). Generally, studies report that those with less power use condoms or contraception less often if they are female (Buysse \& Van Oost, 1997; Jorgensen, et al., 1980). However, Bruhin (2003) found that condoms were used more in clusters where men were more powerful than women. It should be noted however, that very different measures of power were used across these studies.

The impact of power on sexual behaviour may be determined by what we expect men and women to value in sexual relationships. It has been argued that when the power balance in a relationship is unequal, steps will be taken to try to equalize the balance (Emerson, 1962;

Sprecher \& Schwartz, 1994). One way power may be balanced is by offering greater rewards to a partner. For example, a less powerful woman may offer extra resources to her partner in order to balance the relationship, or ensure that her partner is receiving as many rewards from the relationship as herself. What she deems to be of worth to her partner may be determined by what she believes men to want from their partners. There is evidence to suggest that women believe that men do not want to use condoms as often as women do themselves (Bowleg, Lucas, \& Tschann, 2004; Edwards \& Barber, 2010a; Edwards \& Barber, 2010b; Kelly \& Bazzini, 2001; Tschann, Flores, de Groat, Deardorff, \& Wibbelsman, 2010). Additionally, qualitative research suggests that women forgo condom use as a sign of love and care for a male partner, whereas 
men use condoms as a sign of love and care for their female partners (Pulerwitz \& Dworkin, 2006). Other research on the gendered context of sexual behaviour points out that society expects women to be more interested in the use of condoms than men (Campbell, 1995; East, Jackson, O'Brien, \& Peters, 2007; Marston \& King, 2006). It might therefore follow that a woman with less power in a relationship would forgo condom use in order to offer more rewards to her partner in the relationship. In contrast, a man with less power may wear a condom to offer a reward to his partner. However, Tschann and colleagues (2002) did not find that gender and power interacted to predict condom use. Adolescents in Tschann et al.’s study reported condom use with a main sexual partner who they were 'serious about'. Research is yet to investigate this link in casual relationships, and thus it is possible that the gender of one’s partner may be particularly important in casual relationships where patterns of condom use are still developing in the dyad.

Our expectations of men and women may also play a role in predicting unwanted sex. Sex has been described as a resource which women bring to relationships, and that men want (Baumeister \& Vohs, 2004). As an example of this argument, participants from Nigerian focus groups suggested that sex is exchanged for goods among youths, with the understanding that sex was of lesser value to women than to men (Barnett \& Maticka-Tyndale, 2011). Further research indicates that male college students list sex as a reward gained from a relationship, whereas women do not (Sedikides, Oliver, \& Campbell, 1994). Additionally, qualitative research suggests that some women believe that men's desire for sexual gratification is due to the biology of being male, suggesting a belief that male sexual desire is more innate than female sexual desire (Morgan \& Zurbriggen, 2007). Although there is valid argument against the notion that the male sexual desire is more than female sexual desire (Wood, Koch, \& Mansfield, 2006), society 
appears to commonly adopt the viewpoint that men value sex more than women (Leiblum, 2002).

It should then follow that an individual with less power may be more likely to offer sex as a reward to a partner if they are a woman, but not a man. Offering sex as a reward to their partner may take the form of consenting to have sex even when they do not want to. In other words, in order to ensure that a male partner has equal rewards to that of a female partner, women with less power could compensate their partners by having sex with them whenever their partner wants to have sex, including when they feel pressured to. Therefore, holding less power in a relationship may be associated with pressured sex among women.

\section{The Current Study}

The current study aimed to assess how emotional intimacy power predicted condom use and experiencing pressured sex, and how these links were moderated by gender. For the sake of brevity, we use the term 'power' to refer to emotional intimacy power in the context of this study. Most research on power and sexual compliance has focused on romantic relationship experiences, or has not examined relationship contexts separately (e.g. Tschann, et al., 2002). Additionally, Tschann and colleagues only studied adolescents. Thus, there is a lack of research that specifically explores experiences in casual relationships, and there is a lack of research on young adults. The current study aimed to address this gap by extending research on power and sexual behaviour in romantic relationships to casual relationship contexts. The second reason for differentiating between relationship contexts is that condoms are used less in romantic relationships than in casual relationships (Misovich, Fisher, \& Fisher, 1997; Sheeran, Abraham, \& Orbell, 1999), and sexual compliance may be experienced differently in romantic relationships than in casual relationships (Vannier \& O'Sullivan, 2010). Therefore, this study examines sexual 
experiences in both relationship contexts. However, in order to increase the likelihood that individuals in casual relationships were to some degree emotionally invested, and to increase homogeneity in this sub-group, only those who had sex more than once with their partner were included.

With these considerations in mind, the hypotheses of this study varied by relationship context (romantic or casual) and sexual behaviour type (condom use or pressured sex). In terms of condom use, it was hypothesised that participants with more power would use condoms more, if that was consistent with their desires. This finding was expected in both romantic and casual relationship contexts. The interaction between gender and power for condom use was expected to be significant for casual, but not romantic relationship contexts. As past research did not find an interaction between gender and power when predicting condom use in romantic relationships, we also did not expect to find an interaction here (Tschann, et al., 2002). However, there is little past research to inform predictions about casual relationships. Based on the notion that expectations about one's partner's condom use desires may be based on their partner's gender rather than established patterns of condom use, it seems reasonable that gender may be a more salient factor in casual relationships. Therefore, it was hypothesised that individuals with greater power in casual relationships would use condoms more if they were a woman, but less if they were a man.

Predictions about the link between power and pressured sex differed by gender, but not by relationship context. First, it was hypothesised that gender and power would interact to predict pressured sex in both romantic and casual relationship contexts. Predictions about the link between power and pressured sex were based on the societal expectation that men value sex more than women, and on theory that suggests that less powerful individuals offer rewards to partners in an attempt to equalise power imbalances (Emerson, 1962). It was hypothesized that 
women with less power would have sex in response to male partners' pressure more often than women with more power. Due to the limited information available regarding men's experiences with unwanted sex, it was unknown how power would relate to pressured sex for men.

\section{Method}

\section{Participants.}

Participants in this study were taken from a larger sample of Australian university students who responded to an online survey $(\mathrm{n}=1144)$. The larger sample were from a broad range of disciplines with biological sciences, business, veterinary science, media, psychology, and law, each constituting approximately $10 \%$ of respondents, with the remaining $40 \%$ from various other disciplines. The majority of the larger sample was undergraduate students (90.5\%), born in Australia (71\%).

From this larger sample, participants in the current study were selected based on their relationship and sexual experience. Although participants with and without relationship and sexual experiences were encouraged to participate, the current study only examines data from participants who had sex with their partner. Participants were excluded from the current analysis if their partner was of the same sex, given the focus on how power functions in relationships with both a male and female partner. Thus, in this study, 737 students were included in the analyses. Of these students, 708 (70.5\% female, age $M=20.90$ years, $S D=2.06$ ) reported having a romantic sexual relationship experience, and 118 (78.8\% female, age $M=21.12$ years, $S D=$ 2.10) reported having a casual sexual relationship experience. Some participants $(\mathrm{n}=89)$ reported both romantic and casual relationship experiences and were thus included in both 
relationship type analyses. Sample sizes for the analyses that follow may vary due to missing data.

\section{Procedure}

Students responded to an anonymous online survey. Respondents were required to enter their student password which ensured that only the university's students participated, and that they completed the survey only once. Participants accessed the online survey via one of two ways: the School of Psychology homepage or an email sent to the university’s Guild members. Posters were displayed on notice boards at various buildings around the university directing students to the School of Psychology homepage. The response rate was $15.3 \%(\mathrm{~N}=1144)$, based on university enrollment numbers.

\section{Measures}

Relationship Type. Definitions of each relationship type were presented to participants. Romantic relationships were defined as "when you have had a boyfriend or girlfriend. You are both aware that you are in an actual relationship together. You may or may have not have had sex”. Participants were informed that 'sex' referred to sexual intercourse. Participants who had experienced a romantic relationship during the past year were asked to think of their current or most recent partner. They were then asked to think of that one partner when responding to items on relative power and sexual behaviour. Thus, participants' responses are in relation to one relationship, rather than their sexual behaviour in general.

After the romantic relationship section, participants were then asked about 'other' relationship experiences. Definitions of 'other relationships' were presented to participants and included sex with a friend (you are primarily friends but also have had sex), sex with an ex (having sex after you have broken up), a one-night-stand (sex with someone you have just met) 
and other casual relationships (You have been seeing someone casually, but the relationship may not be 'official'. You may be still seeing other people or may be unsure about where you stand with each other. You may or may not have had sex). Participants were then asked to think of one specific partner when responding to items on relative power and sexual behaviour for their 'other' relationship. All 'other' relationships will be referred to as casual relationships in the results below. Although the relationship definitions presented did not require participants to have had sex with their partners, the current study only examines data from those who had. Additionally, only those who had sex with their partner more than once were included in the current analyses.

Due to the organisation of the survey, participants could report one romantic relationship, one casual relationship, or both. Participants who reported experiencing both a romantic and casual relationship experience during the past year $(n=89)$ were presented with two separate sets of relative power and sexual behaviour items.

Power. Participants responded to items measuring the power balance of their relationship, operationalised by the perceived emotional investment discrepancy. Participants rated their own emotional investment, and the perceived emotional investment of their partner on a scale of 1-5. Scale tags were appropriately adjusted to suit the item (e.g. $1=$ Not much, $5=$ A lot). Higher scores indicated higher levels of emotional investment. Items differed according to whether the participant was reporting a romantic or casual relationship.

The emotional investment scale for romantic relationships included six items. Five items were taken from the emotional investment scale used by Tschann and colleagues (2002). For example, "How important is it to you to feel close to your partner?" One item was created for the purpose of the study: “How much do you like/love your partner?” Items assessing perceived 
partner emotional investment were reworded to reflect the required meaning (e.g. "How much does your partner like/love you?”). Cronbach’s alpha was .84 for the participant’s emotional investment items and .87 for the perceived partner's emotional investment items.

The emotional investment scale for casual relationships included four items. One item was adapted from the measure used by Tschann and colleagues (2002), "How close do you want to be to your partner?” Three other items were created specifically for casual relationships. For example “How emotionally intimate do you want to be with your partner?” Cronbach’s alpha was .93 for the participant's emotional investment items and .91 for the perceived partner’s investment items.

The measure of relative power was created by subtracting the participant's own averaged emotional investment score from their perceived partner's averaged emotional investment score. Higher scores on the measure of relative emotional investment indicated that the participant was less emotionally invested, and therefore held more power than their partner.

Pressured Sex. As a measure of pressured sex, participants were asked "How often do you have sex because you are pressured into it?” They reported on a scale of $1-5(1=$ never $-5=$ always; $M=1.33 ; S D=.66$ for romantic relationships; $M=1.36 ; S D=.82$ for casual relationships). The pressured sex item was taken from research on the link between sexual coercion and well-being (McGuire \& Barber, 2010; Zweig, et al., 1997).

Condom Use. Participants were asked how often they used condoms with their partner (1 $=$ never -5 = always $)$ and also how often they wanted to use a condom with their partner $(1=$ never -5 = always). Only participants who wanted to use condoms at least half of the time $(\geq 3)$ were included in the analyses predicting condom use frequency (condom use frequency: $M=$ 
4.05; $S D=1.17$ for romantic relationship participants in this subset; $M=3.73$; $S D=1.61$ for casual relationship participants in this subset).

Birth Control. Participants indicated which method(s) of birth control they generally used with that particular partner from a list of six including: not using birth control, condoms, the pill, and other forms of birth control (e.g. implanon, a diaphragm, having a vasectomy). Many participants in romantic (66\%) and casual (51.3\%) relationships reported using a form of birth control other than condoms. In the analyses that follow, participants were coded with a one if they or their partner were using a form of birth control other than condoms, and a zero if they were not.

\section{Results}

Bivariate associations between gender, power, pressured sex and condom use are first explored. The regression analyses that follow investigate the main effects of power and gender and their interaction. Additionally, as this study focuses on whether power predicted getting one's way with condom use, both the correlational and regression analyses predicting condom use included only those participants who reported wanting to use condoms at least half of the time with their partner (romantic $n=270$; casual $n=69$ ). This restriction meant that getting one's way with condom use would entail more frequent condom use.

Bivariate Analyses of Factors Predicting Pressured Sex and Condom Use.

Bivariate analyses are presented in Table 1. Greater power was significantly related to more condom use in romantic relationships, but this relation did not reach statistical significance in casual relationships. Power was not significantly related to pressured sex in either romantic or casual relationships. Female gender was significantly associated with reporting less relative power in both romantic and casual relationships and within romantic relationship contexts, 
experiencing more pressured sex. Additionally, less condom use was significantly associated with experiencing more pressured sex in both romantic and casual relationships. Using another form of birth control was significantly associated with male gender in romantic relationships, and with less condom use in romantic relationships.

Multivariate Analyses of Factors Predicting Pressured Sex and Condom Use

Multiple linear regression analyses were used to test for predictors of pressured sex and condom use in romantic and casual relationships. In the first step, gender and relative power were entered, and the interaction was entered in the second step. The interaction term was created by multiplying the dummy code for gender with a standardized relative power score. Four different regression analyses were run to investigate how the model predicted two types of sexual behaviour (pressured sex and condom use) in two relationship contexts (romantic and casual). In analyses predicting condom use, being on another form of birth control (such as the contraceptive pill) was controlled in the first step, as this has been associated with less condom use (Sheeran, et al., 1999).

Pressured Sex

Romantic Relationships. At step one of the regression analysis, gender was a significant predictor of pressured sex but relative power was not (Table 2). At step two the interaction term was a significant predictor and was investigated using Modgraph (Jose, 2008) which follows the guidelines of Aiken and West (1991). The nature of the interaction is displayed in Figure 1. Simple slopes were also investigated using Modgraph. As can be seen from the figure, greater relative power predicted having more pressured sex for male participants (slope $=0.13 ; t=4.67$, $p<.01$ ) but not for female participants (slope $=-.00, t=-.04, p>.05$ ). 
Casual Relationships. At the first step of the regression analysis, more relative power significantly predicted more pressured sex, whereas gender did not. At the second step, the interaction of gender and power significantly predicted pressured sex (Table 2). The interaction was investigated using Modgraph and the nature of the interaction appeared similar to that presented for romantic relationships. Simple slope computations showed that greater power significantly predicted more pressured sex for male participants (slope $=0.55 ; t=3.06, p<.01$ ), but not female participants (slope $=.09 ; t=1.01, p>.05$ ).

\section{Condom Use}

Romantic Relationships. At the first step of the regression analysis, greater relative power and not being on another form of birth control significantly predicted more condom use, whereas gender did not (Table 3). At the second step, the interaction of gender and power was not a significant predictor of condom use. Therefore the interaction between gender and power was not investigated further.

Casual Relationships. In casual relationships, the interaction term significantly predicted condom use at the second step, however, no other predictors were significant (Table 3). Modgraph was used to examine the significant interaction which is displayed in Figure 2. Simple slopes revealed that greater power predicted more condom use for women (slope $=0.48 ; t=2.27$, $p<.05$ ) but did not reach significance for men (slope $=-0.81 ; t=-1.70, p>.05$ ). However, the results for men should be interpreted with caution as the number of men included in this subgroup with more favourable condom use desires drops to 11 .

\section{Discussion}

The present study investigated the link between power and sexual behaviour, and found that power predicted sexual behaviour for young adults in romantic and casual relationship contexts. 
In addition to this, the way that power outcomes were experienced by individuals depended upon their gender. It is possible that these patterns reflect the different meaning that sexual experiences have for men and women. The findings regarding the link between power and condom use will first be examined. Then the unexpected findings regarding the link between men's experiences of pressured sex and power and possible explanations for this link will be discussed.

The hypotheses regarding power and condom use were partially supported. Having greater power predicted more frequent condom use in romantic relationships for both men and women who wanted to use condoms more frequently. Therefore, participants with greater power used condoms in a way that was consistent with their own desires. The relationship between power and condom use was similar for men and women in romantic relationships. In casual relationships, greater power predicted more condom use for women, but not men, which was consistent with our hypothesis.

The results add to the current literature on power and sexual behaviour, supporting previous studies on romantic relationships, or undefined relationships, that have found greater power to be associated with more condom use (Buysse \& Van Oost, 1997; Jorgensen, et al., 1980; Pulerwitz, et al., 2002; Pulerwitz, et al., 2000; Woolf \& Maisto, 2008) or condom use that was consistent with what participants wanted (Tschann, et al., 2002; Wang, et al., 2007). The present study extended past research to casual relationship contexts and examined the role of gender in determining the relationship between power and condom use. The fact that the link between power and condom use in casual relationships was only detected when gender was taken into account suggests that predictors of condom use may remain undetected in studies that fail to acknowledge the gendered context of sexual behaviour. The results suggest that power may have 
a differential effect on condom use for men and women in casual, but not romantic relationship contexts.

It could be that gender is a more salient factor in casual relationships than in romantic relationships. For example, in romantic relationships it may be that patterns of condom use have already been established over time, and both partners are aware of the other's desires to use or not to use condoms. Research has found that perceptions of partner attitudes towards condoms predicts condom use (Edwards \& Barber, 2010b; Pallonen, Timpson, Williams, \& Ross, 2009). If the participants in the current study were basing their perceptions of their partner's condom use desires on past patterns of sexual interactions rather than their gender, then this could explain why there was no gender interaction for romantic relationships.

In contrast, in casual relationship contexts, patterns of negotiating condom use and communication about condom use desires may still be developing. In such cases, individuals may rely on their partner's gender as an indicator of their condom use desires, rather than on their previous indications of their desires to use condoms. Thus, in casual relationships the link between power and condom use would be more dependent upon one's partner's gender than in romantic relationships. Gender does appear to play an important role in linking power and condom use in casual relationships and supports the notion that condom use may be determined by exchange processes. Specifically, if condom use is perceived as something of value to women, but not men, then this would explain why greater power predicted more condom use among women, but not men. However, this conclusion should be interpreted with caution due to the small number of men in the casual relationship sample.

The results also add to the small area of research examining the link between power and pressured sex. It was predicted that women with less power would have more pressured sex. 
However, the link between power and pressured sex did not reach significance for women. No predictions were made about how power would relate to unwanted sex among men, but men with greater power reported experiencing more pressured sex in both romantic and casual relationship contexts. There is evidence to suggest that many men report experiencing unwanted sex (Muehlenhard \& Cook, 1988; Vannier \& O'Sullivan, 2010); however, very little is known about the predictors of unwanted sex among men, due to the scant research in this area. The present study makes a valuable contribution to our understanding of the predictors of unwanted sex among men. In attempting to explain why men with more power had more pressured sex it may be important to consider the direction of the relationship. It could be that the experience of pressured sex leads to men perceiving they have more power. To elaborate, it is possible that men are making assumptions about the amount of power they hold in relationships based on whether their partners pressure them for sex. If a man has a female partner who pressures him to have sex, he may assume that she has a high emotional investment in the relationship, and perhaps more so than he does. This would lead to an emotional investment discrepancy score indicating that the man had greater power. Future research could use data from both partners to investigate the intriguing possibility that women who pressure their male partners for sex are not as emotionally invested as their male partners assume, and that their sexual initiative is simply motivated by greater desire for sex, rather than a desire to be emotionally intimate with their partners.

It is also possible that the direction of the relationship between power and pressured sex works in the opposite direction for men: having greater power leads men to be pressured by their female partners for sex. This explanation is consistent with Baumeister and Voh’s (2004) contention that sex is a resource that women give to men. In relationships where the man is more 
powerful, the woman is by definition less powerful, or more invested in the relationship than her partner. If a woman believes that her partner is less emotionally invested in the relationship than she is, she may offer sex as a way to increase the rewards that her partner finds in the relationship. This may take the form of the woman pressuring the man to have sex with her. Future research should investigate this possibility from the woman's perspective, and ideally use both members of couples to determine whether women with less power initiate sex more often and whether such initiations are perceived as pressure by the male partner, and also the female partner.

One final point of interest from the results regarding pressured sex relates to the experiences of those who were less powerful than their partners. Specifically, of those with less power, men appeared to have less pressured sex than women. This may be explained by the finding that being female was associated with having more pressured sex than men in general, and therefore it would be expected that women with less power would have more pressured sex than men.

\section{Practical Implications}

The link between power and sexual behavior may be of interest to clinicians or those working in sexual health. Many women in this study reported experiencing pressured sex, and given that pressured sex has been associated with reduced well-being among women (Zweig, Barber \& Eccles, 1997), it seems that clinicians should be alert to the possible impact this behaviour could have on female clients. The current findings may also be useful for clinicians working with couples. In particular, this research may improve our understanding of how sexual behavior can be used as a resource exchanged between men and women to balance power in relationships. 
In promoting sexual health, it may be helpful to encourage individuals to challenge their perceptions of low power in relationships. If young adults are underestimating how emotionally invested their partners are, they may indeed have more power than they think, which could increase their confidence in negotiating condom use.

\section{Limitations and Directions for Future Research}

A number of limitations must be kept in mind when interpreting these findings. First, the direction of effects can not be determined from the present study. This is a limitation that is shared with other cross-sectional research. Second, the measurement of pressured sex was a oneitem measure with an unknown reliability. Although this scale has been used in other published articles (McGuire \& Barber, 2010; Zweig, et al., 1997), it is possible that the findings may have differed if a more comprehensive measure of pressured sex was used. Third, only a small amount of variability was explained in the regression analyses for pressured sex and condom use. Obviously, there are many other factors that contribute to sexual behaviour in young adult relationships.

A final limitation is regarding the small number of male participants in casual relationships. For pressured sex, the same pattern emerged in men's casual relationships as in their romantic relationships and so, even if the sample of male casual relationships was greater, it is possible that more power would predict more pressured sex among men. For condom use, the power by gender interaction was not significant in romantic relationships, but was in casual relationships. Future research should investigate whether this finding is replicated in a larger male sample, when more statistical power would be available. 


\section{Conclusions}

The current research makes an important contribution to the area of research on power and sexual behaviour. Little is known about how power relates to unwanted sex, especially among men, and even less is known about men's experiences in casual relationships. Our results suggest that potential power, as measured by participants’ emotional investment discrepancy, predicts sexual experiences for young adults. Individuals with less power may look to the sexual aspect of their relationship as a way to increase the rewards that their partner is receiving from the relationship, and thus restore balance. In some cases, this may take the form of forgoing condom use, or pressuring their partners for sex. It also appears that the link between power and sexual experiences may depend on what we expect men and women to value. Specifically, the results shed light on the meanings that condom use and sex have for men and women. In particular, sex may be seen as something that women give to men, and at least in casual relationships, condom use as something that men give to women. 


\section{References:}

Aiken, L. S., \& West, S. G. (1991). Multiple regression: Testing and interpreting interactions. Newbury Park, CA: Sage Publications, Inc.

Bacharach, S. B., \& Lawler, E. J. (1981). Bargaining, power, tactics, and outcomes. San Francisco: Jossey-Bass.

Barnett, J. P., \& Maticka-Tyndale, E. (2011). The gift of agency: Sexual exchange scripts among Nigerian youth. Journal of Sex Research, 48(4), 349-349-359.

Baumeister, R. F., \& Vohs, K. D. (2004). Sexual economics: Sex as female resource for social exchange in heterosexual interactions. Personality and Social Psychology Review, 8(4), 339-363.

Billy, J. O. G., Grady, W. R., \& Sill, M. E. (2009). Sexual risk-taking among adult dating couples in the United States. Perspectives on Sexual and Reproductive Health, 41(2), 7474-83.

Bowleg, L., Lucas, K. J., \& Tschann, J. M. (2004). "The ball was always in his court": An exploratory analysis of relationship scripts, sexual scripts, and condom use among African American women. Psychology of Women Quarterly, 28(1), 70-82.

Bralock, A. R., \& Koniak-Griffin, D. (2007). Relationship, power, and other influences on selfprotective sexual behaviors of African American female adolescents. Health Care for Women International, 28(3), 247-267.

Bruhin, E. (2003). Power, communication and condom use: Patterns of HIV-relevant sexual risk management in heterosexual relationships. AIDS Care, 15(3), 389-401.

Buysse, A., \& Van Oost, P. (1997). 'Appropriate' male and female safer sexual behaviour in heterosexual relationships. AIDS Care, 9(5), 549-561. 
Cabral, R. J., Pulley, L., Artz, L. M., Brill, I., \& Macaluso, M. (1998). Women at risk of HIV/STD: The importance of male partners as barriers to condom use. AIDS and Behavior, 2(1), 75-85.

Campbell, C. A. (1995). Male gender roles and sexuality: Implications for women's AIDS risk and prevention. Social Science \& Medicine, 41(2), 197-210.

East, L., Jackson, D., O'Brien, L., \& Peters, K. (2007). Use of the male condom by heterosexual adolescents and young people: Literature review. Journal of Advanced Nursing, 59(2), 103-110.

Edwards, G. L., \& Barber, B. (2010a). The relationship between rejection sensitivity and compliant condom use. Archives of Sexual Behavior, 39(6), 1381-1388.

Edwards, G. L., \& Barber, B. L. (2010b). Women may underestimate their partners’ desires to use condoms: Possible implications for behaviour. Journal of Sex Research, 47(1), 59-65.

Emerson, R. M. (1962). Power-dependence relations. American Sociological Review, 27(1), 3041.

Felmlee, D. H. (1994). Who's on top? Power in romantic relationships. Sex Roles, 31(5-6), 275295.

Harvey, S. M., Bird, S. T., Galavotti, C., Duncan, E. A. W., \& Greenberg, D. (2002). Relationship power, sexual decision making and condom use among women at risk for HIV/STDs. Women \& Health, 36(4), 69-84.

Impett, E. A., \& Peplau, L. A. (2003). Sexual compliance: Gender, motivational, and relationship perspectives. Journal of Sex Research, 40(1), 87-100. 
Jorgensen, S. R., King, S. L., \& Torrey, B. A. (1980). Dyadic and social network influences on adolescent exposure to pregnancy risk. Journal of Marriage \& the Family, 42(1), 141155.

Jose, P. E. (2008). ModGraph-I: A programme to compute cell means for the graphical display of moderational analyses: The internet version, Version 2.0. Retrieved 15-12, 2008, from http://www.victoria.ac.nz/psyc/staff/paul-jose-files/modgraph/modgraph.php

Kelly, J., \& Bazzini, D. G. (2001). Gender, sexual experience, and the sexual double standard: Evaluations of female contraceptive behavior. Sex Roles, 45(11/12), 785-799.

Leiblum, S. R. (2002). Reconsidering gender differences in sexual desire: An update. Sexual and Relationship Therapy, 17(1), 57-68.

Marston, C., \& King, E. (2006). Factors that shape young people's sexual behavior: A systematic review. Lancet, 368(9547), 1581-1586.

McGuire, J. K., \& Barber, B. L. (2010). A person-centered approach to the multifaceted nature of young adult sexual behavior. Journal of Sex Research, 47(4), 301-301-313.

Misovich, S. J., Fisher, J. D., \& Fisher, W. A. (1997). Close relationships and elevated HIV risk behavior: Evidence and possible underlying psychological processes. Review of General Psychology, 1(1), 72-107.

Moore, S., \& Rosenthal, D. (2006). Sexuality in adolescence: Current trends (2nd ed.). London: Routledge.

Morgan, E. M., \& Zurbriggen, E. L. (2007). Wanting sex and wanting to wait: Young adults' accounts of sexual messages from first significant dating partners. Feminism \& Psychology, 17(4), 515-541. 
Muehlenhard, C. L., \& Cook, S. W. (1988). Men's self-reports of unwanted sexual activity. Journal of Sex Research, 24, 58-72.

O'Sullivan, L. F., \& Allgeier, E. R. (1998). Feigning sexual desire: Consenting to unwanted sexual activity in heterosexual dating relationships. Journal of Sex Research, 35(3), 234243.

Pallonen, U. E., Timpson, S. C., Williams, M. L., \& Ross, M. W. (2009). Stages of consistent condom use, partner intimacy, condom use attitude, and self-efficacy in AfricanAmerican crack cocaine users. Archives of Sexual Behavior, 38(1), 149-158.

Pulerwitz, J., Amaro, H., De Jong, W., Gortmaker, S. L., \& Rudd, R. (2002). Relationship power, condom use and HIV risk among women in the USA. AIDS Care, 14(6), 789-800.

Pulerwitz, J., \& Dworkin, S. L. (2006). Give-and-take in safer sex negotiations: The fluidity of gender-based power relations. Sexuality Research \& Social Policy: A Journal of the NSRC, 3(3), 40-51.

Pulerwitz, J., Gortmaker, S. L., \& DeJong, W. (2000). Measuring sexual relationship power in HIV/STD research. Sex Roles, 42(7-8), 637-660.

Rusbult, C. E., \& Buunk, B. P. (1993). Commitment processes in close relationships: An interdependence analysis. Journal of Social and Personal Relationships. Special Issue: Relational maintenance, 10(2), 175-204.

Sedikides, C., Oliver, M. B., \& Campbell, W. K. (1994). Perceived benefits and costs of romantic relationships for women and men: Implications for exchange theory. Personal Relationships, 1(1), 5-21.

Sheeran, P., Abraham, C., \& Orbell, S. (1999). Psychosocial correlates of heterosexual condom use: A meta-analysis. Psychological Bulletin, 125(1), 90-132. 
Sionean, C., DiClemente, R. J., Wingood, G. M., Crosby, R., Cobb, B. K., Harrington, K., et al. (2002). Psychosocial and behavioral correlates of refusing unwanted sex among AfricanAmerican adolescent females. Journal of Adolescent Health, 30(1), 55-63.

Sprecher, S., \& Felmlee, D. (1997). The balance of power in romantic heterosexual couples over time from "his" and "her" perspectives. Sex Roles, 37, 5-6.

Sprecher, S., Schmeeckle, M., \& Felmlee, D. (2006). The principle of least interest: Inequality in emotional involvement in romantic relationships. Journal of Family Issues, 27(9), 12551280.

Sprecher, S., \& Schwartz, P. (1994). Equity and balance in the exchange of contributions in close relationships. New York: Plenum Press.

Teitelman, A. M., Ratcliffe, S. J., Morales-Aleman, M. M., \& Sullivan, C. M. (2008). Sexual relationship power, intimate partner violence, and condom use among minority urban girls. Journal of Interpersonal Violence, 23(12), 1694-1712.

Thibaut, J. W., \& Kelley, H. H. (1959). The social psychology of groups. Oxford, England: Wiley.

Tschann, J. M., Adler, N. E., Millstein, S. G., Gurvey, J. E., \& Ellen, J. M. (2002). Relative power between sexual partners and condom use among adolescents. Journal of Adolescent Health, 31(1), 17-25.

Tschann, J. M., Flores, E., de Groat, C. L., Deardorff, J., \& Wibbelsman, C. J. (2010). Condom negotiation strategies and actual condom use among Latino youth. Journal of Adolescent Health, 47(3), 254-254-262. 
Vannier, S. A., \& O'Sullivan, L. F. (2010). Sex without desire: Characteristics of occasions of sexual compliance in young adults' committed relationships. Journal of Sex Research, 47, 429-439.

Waller, W., \& Hill, R. (1951). The family: a dynamic interpretation. New York: Dryden Press.

Wang, R.-H., Wang, H.-H., \& Hsu, H.-Y. (2007). A relationship power scale for female adolescents: Preliminary development and psychometric testing. Public Health Nursing, 24(1), 81-90.

Wood, J. M., Koch, P. B., \& Mansfield, P. K. (2006). Women's sexual desire: A feminist critique. Journal of Sex Research, 43(3), 236-244.

Woolf, S. E., \& Maisto, S. A. (2008). Gender differences in condom use behavior? The role of power and partner-type. Sex Roles, 58(9-10), 689-701.

Zweig, J. M., Barber, B. L., \& Eccles, J. S. (1997). Sexual coercion and well-being in young adulthood: Comparisons by gender and college status. Journal of Interpersonal Violence, 12(2), 291-308. 
Table 1

Bivariate associations between gender, emotional intimacy power, and sexual behaviour. Casual and romantic relationships are presented on the upper and lower diagonals respectively.

\begin{tabular}{|c|c|c|c|c|c|}
\hline Variables & 1 & 2 & 3 & 4 & 5 \\
\hline \multirow[t]{2}{*}{ 1. Birth Control ${ }^{\mathrm{a}}$} & - & .01 & .03 & $-.29 * *$ & -.01 \\
\hline & & $\mathrm{n}=117$ & $\mathrm{n}=117$ & $\mathrm{n}=108$ & $\mathrm{n}=70$ \\
\hline \multirow[t]{2}{*}{ 2. Gender† } & $-.08 *$ & - & $-.39 * *$ & .04 & -.12 \\
\hline & $\mathrm{n}=692$ & & $\mathrm{n}=118$ & $\mathrm{n}=108$ & $\mathrm{n}=70$ \\
\hline \multirow[t]{2}{*}{ 3. Emotional Intimacy Power } & .01 & $-.14^{*}$ & - & .18 & .19 \\
\hline & $\mathrm{n}=685$ & $\mathrm{n}=695$ & & $\mathrm{n}=108$ & $\mathrm{n}=70$ \\
\hline \multirow[t]{2}{*}{ 4. Pressured sex } & -.01 & $.11^{*}$ & .03 & - & $-.30 *$ \\
\hline & $\mathrm{n}=660$ & $\mathrm{n}=664$ & $\mathrm{n}=658$ & & $\mathrm{n}=69$ \\
\hline \multirow[t]{2}{*}{ 5. Condom Use } & $-.24 * *$ & -.08 & $.12 *$ & $-.28^{* *}$ & - \\
\hline & $\mathrm{n}=275$ & $\mathrm{n}=277$ & $\mathrm{n}=277$ & $\mathrm{n}=278$ & \\
\hline
\end{tabular}

Note: ${ }^{*} p<.05 .{ }^{* *} p<.01 . ;{ }^{\text {a }}$ Non-use $=0$, Use $=1 . ; \dagger$ Male $=0$, Female $=1$. Correlations with condom use only include those who wanted to use condoms at least half of the time. 
Table 2

Summary of Hierarchical Regression Analysis for Variables Predicting Pressured Sex Among Sexually Experienced Individuals in Romantic (n

= 654) and Casual Relationships $(n=107)$.

\begin{tabular}{|c|c|c|c|c|c|c|c|c|c|c|c|c|}
\hline & \multicolumn{6}{|c|}{ Romantic Relationships } & \multicolumn{6}{|c|}{ Casual Relationships } \\
\hline & \multicolumn{3}{|c|}{ Model 1} & \multicolumn{3}{|c|}{ Model 2} & \multicolumn{3}{|c|}{ Model 1} & \multicolumn{3}{|c|}{ Model 2} \\
\hline Variable & $B$ & $S E B$ & $\beta$ & $B$ & $S E B$ & $\beta$ & $B$ & SE B & $\beta$ & $B$ & $S E B$ & $\beta$ \\
\hline Gender† & .18 & .06 & $.12^{* *}$ & .20 & .06 & $.13^{* *}$ & .25 & .21 & .12 & .54 & .24 & $.27^{*}$ \\
\hline Power & .04 & .03 & .05 & .13 & .05 & $.19 *$ & .17 & .08 & $.23^{*}$ & .55 & .18 & $.73^{* *}$ \\
\hline G x P Interaction & & & & -.13 & .06 & $-.16^{*}$ & & & & -.46 & .20 & $-.52 *$ \\
\hline Adjusted $R^{2}$ & & .01 & & & .02 & & & .03 & & & .07 & \\
\hline$F$ for change in $R^{2}$ & & $5.00^{* *}$ & & & $4.76^{*}$ & & & 2.43 & & & $3.53^{*}$ & \\
\hline
\end{tabular}

Note: $* p<.05 . * * p<.01 . ; \dagger$ Male $=0$, Female $=1$. 
Table 3

Summary of Hierarchical Regression Analysis for Variables Predicting Condom Use Among Sexually Experienced Individuals in Romantic

Relationships who wanted to use condoms at least half of the time $(n=270)$ and Casual Relationships $(n=69)$.

\begin{tabular}{|c|c|c|c|c|c|c|c|c|c|c|c|c|}
\hline & \multicolumn{6}{|c|}{ Romantic Relationships } & \multicolumn{6}{|c|}{ Casual Relationships } \\
\hline & \multicolumn{3}{|c|}{ Model 1} & \multicolumn{3}{|c|}{ Model 2} & \multicolumn{3}{|c|}{ Model 1} & \multicolumn{3}{|c|}{ Model 2} \\
\hline Variable & $B$ & SE B & $\beta$ & $B$ & SE B & $\beta$ & $B$ & $S E B$ & $\beta$ & $B$ & $S E B$ & $\beta$ \\
\hline Birth Control Use $^{\mathrm{a}}$ & -.54 & .14 & $-.23 * *$ & -.54 & .14 & $-.23 * *$ & .01 & .39 & .00 & .16 & .38 & .05 \\
\hline Gender† & -.10 & .15 & -.04 & -.10 & .16 & -.04 & -.33 & .55 & -.07 & -1.02 & .60 & -.23 \\
\hline Power & .14 & .07 & $.12 *$ & .10 & .14 & .09 & .27 & .20 & .17 & -.81 & .47 & -.51 \\
\hline G x P Interaction & & & & .04 & .16 & .03 & & & & 1.29 & .52 & $.71^{*}$ \\
\hline Adjusted $R^{2}$ & & .06 & & & .06 & & & -.00 & & & .07 & \\
\hline$F$ for change in $R^{2}$ & & $6.81^{* *}$ & & & .07 & & & .95 & & & $6.11^{*}$ & \\
\hline
\end{tabular}

Note: ${ }^{*} p<.05 .{ }^{* *} p<.01 . ; \dagger$ Gender: Male $=0$, Female $=1 .{ }^{\text {a }}$ Birth Control Use: Non-use $=0$, Use $=1$. 


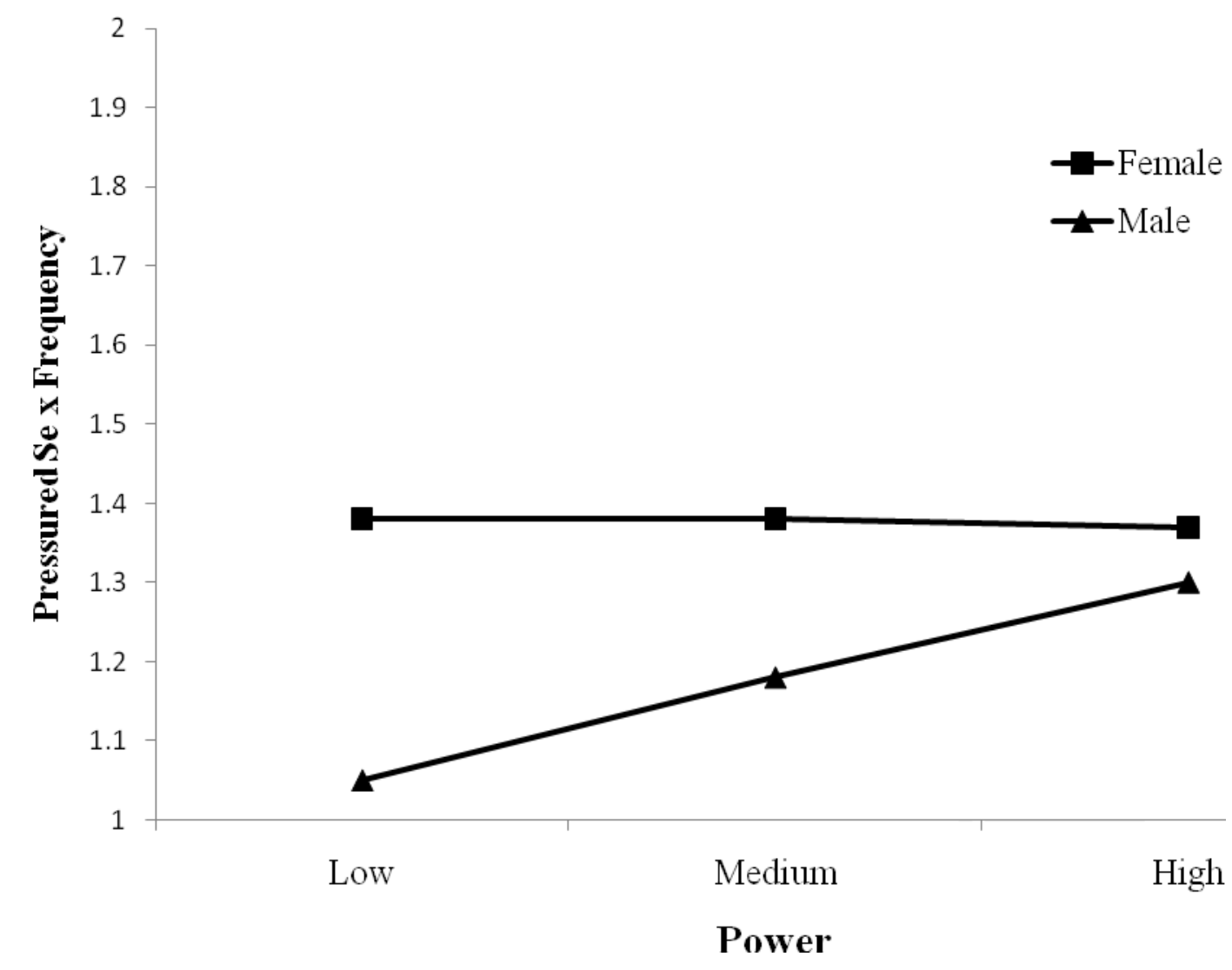

Figure 1. Power as a predictor of pressured sex in romantic relationships for men and women. 


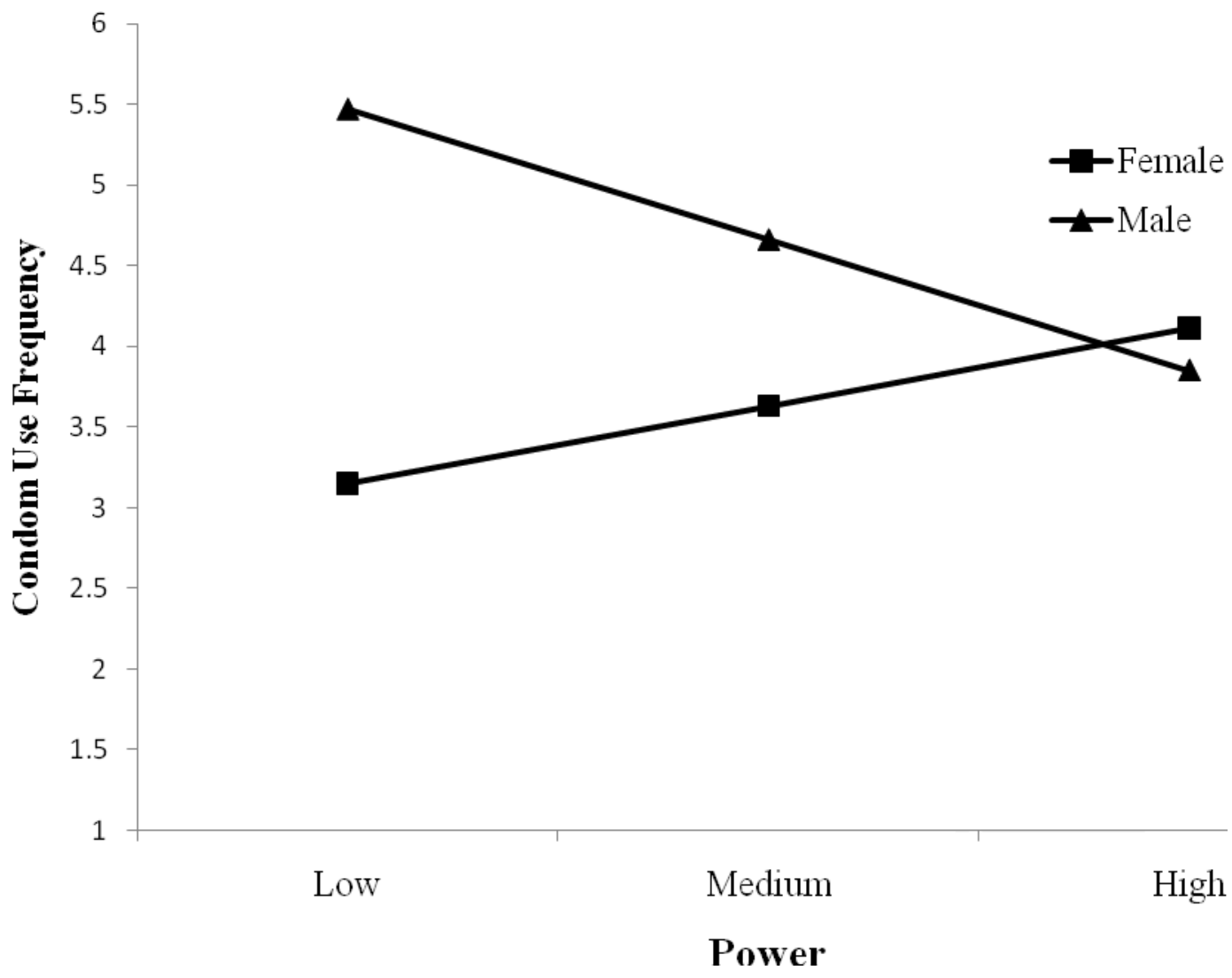

Figure 2. Power as a predictor of condom use in casual relationships for men and women. 